\title{
Effects of Deposition Thickness on Electrochemical Behaviors of AZ31B Magnesium Alloy with Composite Coatings Prepared by Micro-arc Oxidation and Electrophoretic Deposition
}

\author{
Ming Wu ${ }^{1}$, Yanhua Guo ${ }^{1, *}$, Guanglong $X u^{1}$,Yuwen $C u i^{1,2, *}$ \\ ${ }^{1}$ Tech Institute of Advanced Materials \& College of Materials Science and Engineering, Nanjing Tech \\ University, 210009, Nanjing, China \\ 2 ICMA, CSIC-Universidad de Zaragoza, 50009 Zaragoza, Spain \\ *E-mail: guoyanhua@njtech.edu.cn, ycui@ njtech.edu.cn
}

Received: 24 April 2019 / Accepted: 21 November 2019 / Published: 31 December 2019

\begin{abstract}
Two types of coatings with different deposition thicknesses were prepared on AZ31B Mg alloy by microarc oxidation (MAO) and micro-arc oxidation plus electrophoretic deposition (MAO/EPD) techniques. The surface morphology, cross section and phase composition of two type coatings were studied by scanning electron microscopy and X-ray diffraction. The corrosion performance of the coatings was investigated via electrochemical and immersion experiments. The results indicated that corrosion resistance of MAO coating did not monotonously enhance with the increase of the period of deposition time; instead, it displayed a close relation with the thickness of the coating dense layer. The corrosion resistance of MAO/EPD coating was upgraded with the composite coating. Compared with MAO coating, MAO/EPD coating was found more effective in isolating the substrate from the corrosive environment. It was attributed to EPD coating composite that greatly reduces the micro-porosity and microcrack defects of MAO coating.
\end{abstract}

Keywords: micro-arc oxidation; electrophoretic deposition; coating thickness; microstructure; corrosion behaviour

\section{INTRODUCTION}

Magnesium and magnesium alloys attract wide attentions from industries such as automotive, aerospace and communication owing to the characteristics of lightweight, good thermal conductivity, high specific mechanical strength and good microwave shielding property [1]. Unfortunately, poor corrosion resistance limits the use of magnesium in harsh environments [2-3]. Therefore, it is crucial to improve the corrosion resistance of magnesium alloys. To date, the use of various coatings on 
magnesium substrate is the most effective method to prevent magnesium from corrosion, such as metal coating [4-5], organic coating [6], anodizing [7-8] and conversion coating [9]. Although these surface treatments help to improve the corrosion resistance of magnesium alloys, the preparations of these coatings are subjected to complex procedures and do harm to the environment.

Micro-arc oxidation (MAO) has been proven an effective technique of surface treatment for $\mathrm{Mg}$, $\mathrm{Al}$, Ti alloys [10-12]. It brings significant improvement in wear resistance, corrosion resistance, and mechanical strength of magnesium alloys [13-15]. Nevertheless, due to continuous and strong spark discharge and gas bubbling, MAO is inclined to form porous structures on the surface [16-17]. It increases the possibility of corrosive electrolytes permeating in the later period of service, thus leads to magnesium corrosion.

The electrophoretic deposition (EPD) is another promising method to prepare protective coatings with high corrosion resistance and good adhesion to both metallic substrates and top coatings [18]. The short deposition time makes it applicable to any solid in the form of a fine powder or colloidal suspension. Owing to the simple facilities and few restrictions on the shape of substrate, EPD has been accepted as an economical and effective surface treatment [19]. MAO/EPD combined technique can reduce the microporous and microcracks on the MAO coating. Great efforts have been made to compare the microstructure and corrosion resistance of magnesium alloys w/o EPD and/or MAO. Nevertheless, a systematic investigation addressing the different effects between MAO and MAO/EPD on the electrochemical behaviours of magnesium alloy is still required. It can boost the processing optimization in MAO and MAO/EPD treatments.

In present work, MAO and MAO/EPD surface treatments were individually employed to prepare the composite coatings on AZ31B magnesium alloy. Microstructure, chemical and phase compositions, electrochemical behaviours, and corrosion resistance of magnesium alloys with MAO and MAO/EPD coatings were investigated.

\section{MATERIALS AND METHODS}

A commercial AZ31B magnesium alloy with the chemical composition of $\mathrm{Mg}-3.2 \mathrm{Al}-0.82 \mathrm{Zn}-$ $0.35 \mathrm{Mn}-0.03 \mathrm{Si}-0.05 \mathrm{Ca}-0.005 \mathrm{Fe}$ wt. $\%$ was used as substrate material. The AZ31B alloy was cut into disc specimens with a thickness of $3 \mathrm{~mm}$ and a diameter of $50 \mathrm{~mm}$. Prior to the MAO process, the specimens were firstly polished with $\mathrm{SiC}$ abrasive paper from 200 grade to 2000 grade. The coating process was implemented in an alkaline electrolyte containing $5.0 \mathrm{~g} / \mathrm{L} \mathrm{Na}_{2} \mathrm{SiO}_{3} \cdot 9 \mathrm{H}_{2} \mathrm{O}, 8.0 \mathrm{~g} / \mathrm{L} \mathrm{KF} \cdot 2 \mathrm{H}_{2} \mathrm{O}$ and $10.0 \mathrm{~g} / \mathrm{L} \mathrm{NaOH}$. The pulse width was set $80 \mu \mathrm{s}$, the frequency was set $500 \mathrm{~Hz}$, and the current density was $7.8 \mathrm{~A} \mathrm{dm}^{-2}$. Different periods ( $5 \mathrm{~min}, 10 \mathrm{~min}$, and $15 \mathrm{~min}$ ) of oxidation time were adopted to obtain the different thickness coatings $(\sim 5 \mu \mathrm{m}, 11 \mu \mathrm{m}, 15 \mu \mathrm{m})$ in MAO treatment. The temperature of the electrolyte solution was maintained at $\sim 20^{\circ} \mathrm{C}$ by adjusting the temperature of cooling water during the treatment process. To obtain the MAO/EPD coatings, the MAO-coated AZ31B specimens with the same deposition time were then immersed in a cathodic HG-91 E-coating bath solution $(60 \mathrm{wt} . \%$ deionized water, $30 \mathrm{wt} . \%$ HG-90 emulsion and $10 \mathrm{wt} \%$ HG-90 matte color paste) at voltages of $60 \mathrm{~V}, 80 \mathrm{~V}, 100$ $\mathrm{V}$ respectively for different thickness coatings $(\sim 10 \mu \mathrm{m}, 15 \mu \mathrm{m}, 20 \mu \mathrm{m})$. Afterward, the specimens were cleaned with deionized water and then put in an oven at $220{ }^{\circ} \mathrm{C}$ for $20 \mathrm{~min}$. 
The microstructures of the specimens were observed by Field Emission Scanning Electron Microscopy (FE-SEM, JSM-6700F, JEOL, Tokyo, Japan). Phase composition of the coatings were analysed by X-ray diffraction (XRD, DMAX-RB, Rigaku, Tokyo, Japan, $\mathrm{Cu} \mathrm{K} \alpha$ ) using $\mathrm{Cu}$ K $\alpha$ radiation with $2 \theta$ of $20-80^{\circ}$.

The potentiodynamic polarization and electrochemical impedance spectroscopy (EIS) were adopted to evaluate the corrosion resistance properties of MAO and MAO/EPD coatings. They were carried out on CHI660D (Shanghai, China). In three-electrode cells, a platinum plate was used as the counter electrode, and $\mathrm{Ag} / \mathrm{AgCl}$ was used as the reference electrode. The working electrode was the coated sample. The exposed area of the working electrode was $0.5 \mathrm{~cm}^{2}$. It was immersed into the electrolyte of 3.5 wt.\% $\mathrm{NaCl}$ at room temperature. Half an hour later, EIS was performed with a perturbation amplitude of $10 \mathrm{mV}$ and a test frequency ranging $10^{5} \mathrm{~Hz}-1 \mathrm{~Hz}$. After $1 \mathrm{~h}$ immersion, the potentiodynamic polarization test was conducted at a rate of $5 \mathrm{mV} / \mathrm{s}$. A $3.5 \mathrm{wt}$. $\% \mathrm{NaCl}$ solution was used in immersion experiment to evaluate the long-term corrosion behavior of the samples and the soaked solution was replaced every $24 \mathrm{~h}$. During the replacement, the sample was washed with deionized water and dried in the air, and the changes on the surface of the sample were recorded by photos.

\section{RESULTS AND DISCUSSION}

\subsection{Microstructure}

The SEM images of the surface and the cross-section of MAO coatings are shown in Figure 1. The morphology changes with different periods of deposition time. The typical "crater-like" micropores are found on the surface of MAO coating. The formation of the micropores may be related to the gas bubbles out of the micro-arc discharge channels and thermal stress concentrated in the solidified molten oxide [20]. The surface discharge micropores increase in size and decrease in amount with the microarc oxidation time prolongs. Meanwhile, more defects can be observed. It can be explained by the fact that the increasing deposition times of the ceramic layer leads to enlarged impedance value of the surface increases. In the constant current mode, the voltage rise increases the energy of a single pulse, and the volume of the melt produced by the ceramic layer during the breakdown discharge grows, resulting in an increase in the size of the micropores remaining after the discharge channel is condensed. The formation of these micropores and microcracks is detrimental to corrosion resistance of MAO coating. Figure 1(b, d, f) shows the morphology of the cross-sections of the MAO-coated AZ31B magnesium alloy. They are composed of a porous layer on the top and a thin dense layer between top layer and AZ31B substrate. Owing to the chemical bonding in the MAO process, the dense layer and the substrate are jointed compactly [21]. The thickness and the compactness of the dense layer change with oxidation time. For 5-10 min, the dense layer become thick with time and kept compact. However, when the oxidation time reached $15 \mathrm{~min}$, the thickness of the dense layer decreases and a large number of defects appeared. 

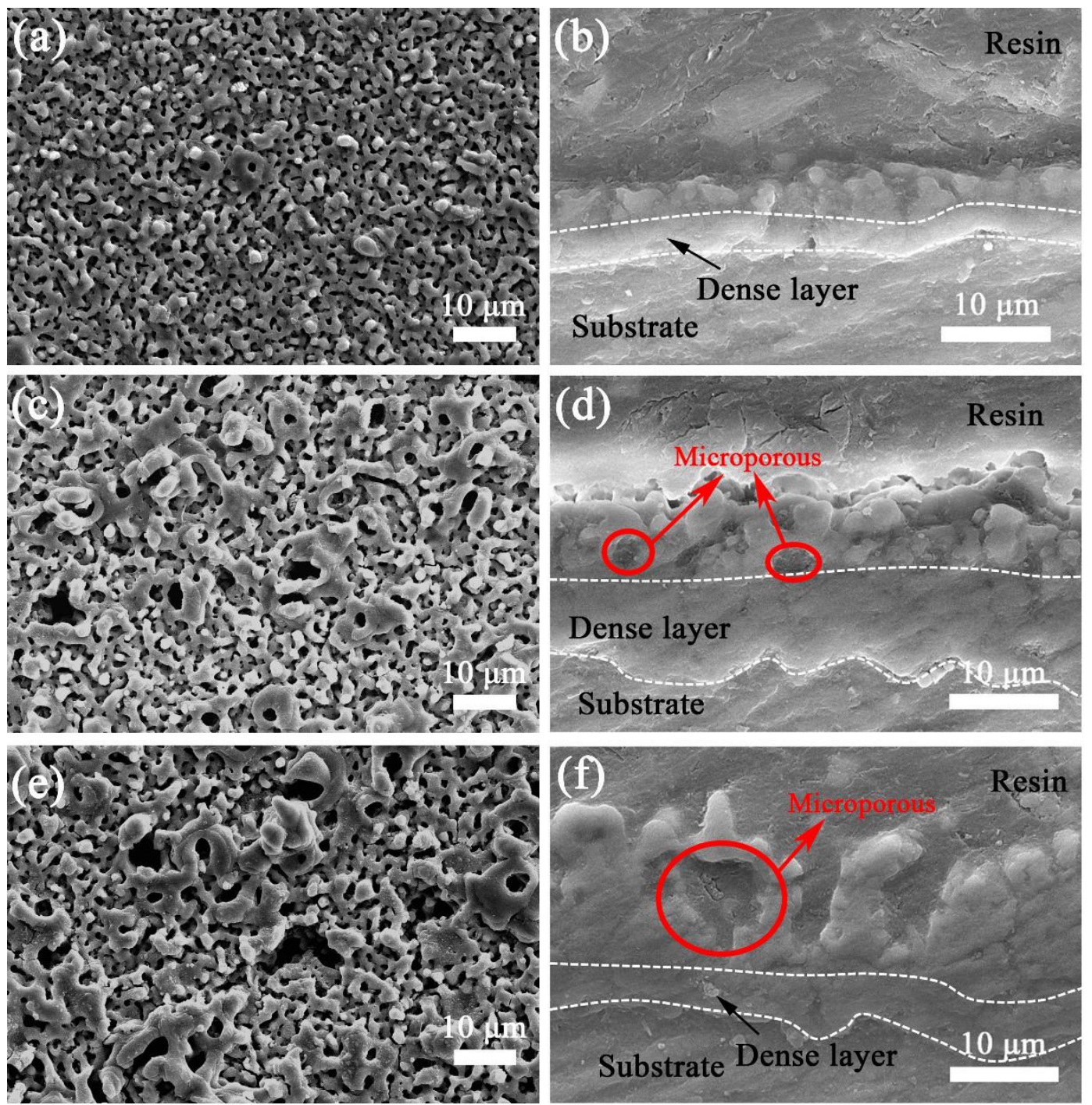

Figure 1. SEM micrographs of the surface and the cross-sections of the MAO coated AZ31B with different oxidation time: (a b) $5 \mu \mathrm{m}$; (c d) $11 \mu \mathrm{m}$; (e f) $15 \mu \mathrm{m}$.

The SEM images of the surface and the cross-section of MAO/EPD coated alloys are shown in Figure 2. It is clear that MAO with an EPD coating is able to obtain a smooth and non-porous surface. From the cross-section, MAO/EPD coating consists of the organic EPD coating, and the layer of MAO. The epoxy resin contributes a smooth and compact surface without any defects. The organic EPD coating is observed to reach the dense inner layer through the porous outer layer of MAO, and the mechanical interlocking between the EPD coating and the rough interface of the discharge channel is tightly combined through the discharge channel. The thickness of the EPD coating is proportional to the oxidation voltage. 

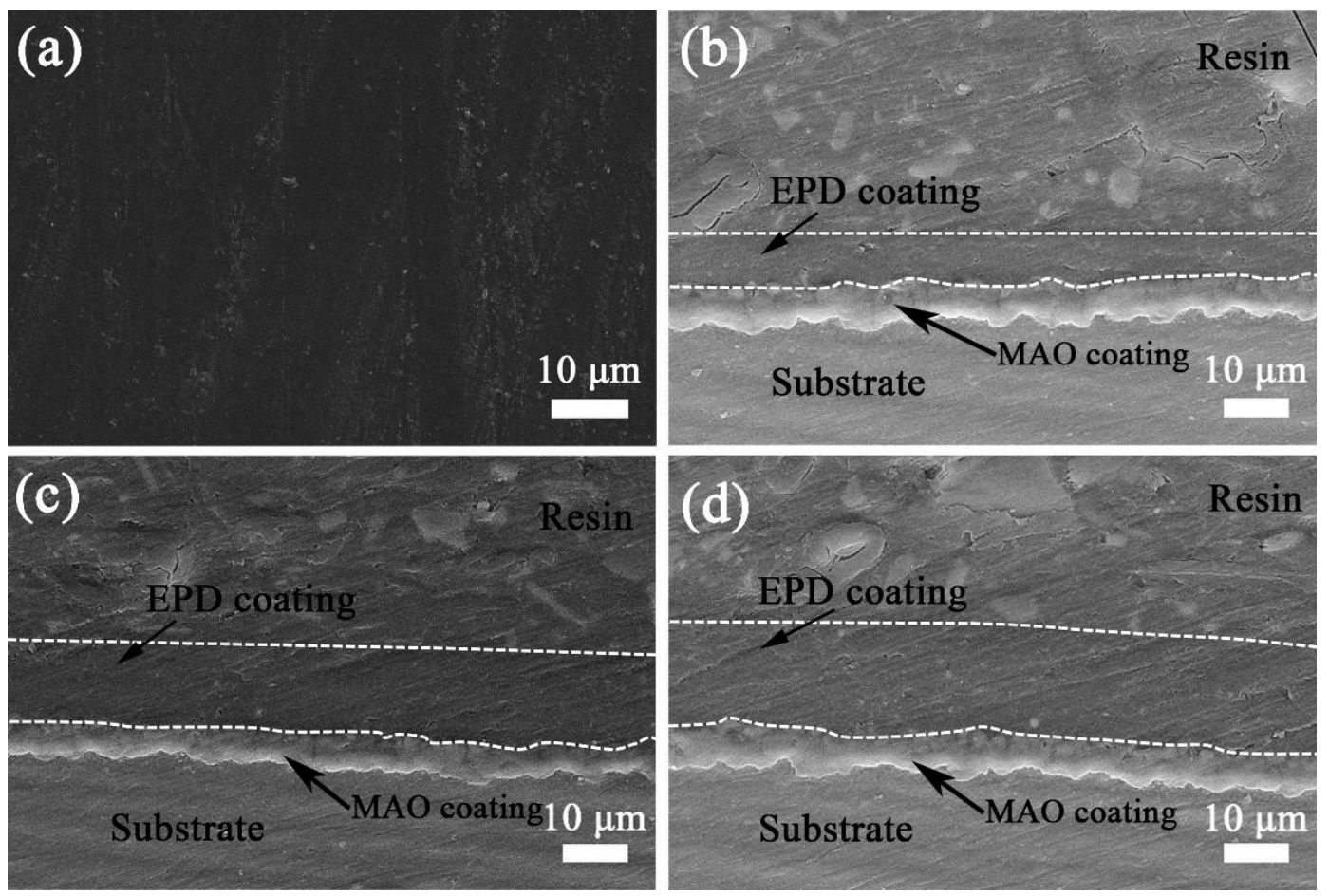

Figure 2. SEM micrographs of (a) the surface and the cross-sections of the MAO coated AZ31B. (b-d) are associated with different thickness: (b) $10 \mu \mathrm{m}$, (c) $15 \mu \mathrm{m}$, (d) $20 \mu \mathrm{m}$.

\subsection{Phase Composition}

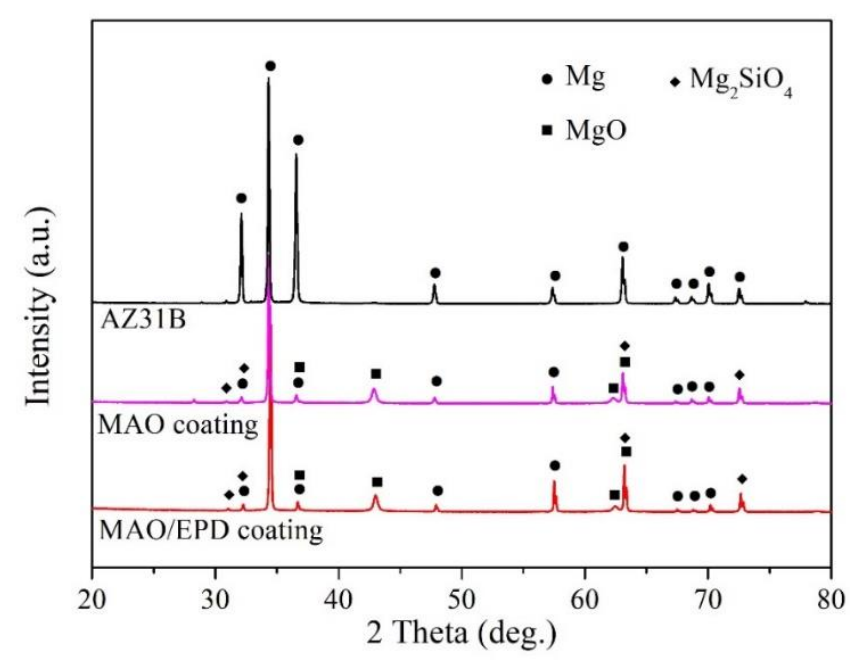

Figure 3. XRD patterns of the MAO and MAO/EPD coating on AZ31B magnesium alloy.

Figure 3 shows the XRD patterns of the MAO and MAO/EPD coated AZ31B in comparison to AZ31B alloy without coating. The diffraction peaks are predominately Mg solid solution for the AZ31B. However, the MAO and MAO/EPD coated samples show other diffraction peaks of $\mathrm{Mg}_{2} \mathrm{SiO}_{4}$ and $\mathrm{MgO}$ besides Mg. There is no difference of phase composition between MAO and MAO/EPD coated samples, indicating hardly an effect of electrophoretic treatment on the phase composition. The phase formation 
mechanism of AZ31B magnesium alloy MAO coating in the silicate electrolyte has already been reported [22].

\subsection{Electrochemical Corrosion Behavior}

\subsubsection{Electrochemical test of MAO coatings}

The potentiodynamic polarization curves of MAO coatings with different thickness are displayed in Figure 4. Tafel extrapolation [23,24] was employed to obtain the corrosion potential ( $E_{\text {corr }}$ and corrosion current density $\left(i_{\text {corr }}\right)$. The measured values are listed in Table 1.

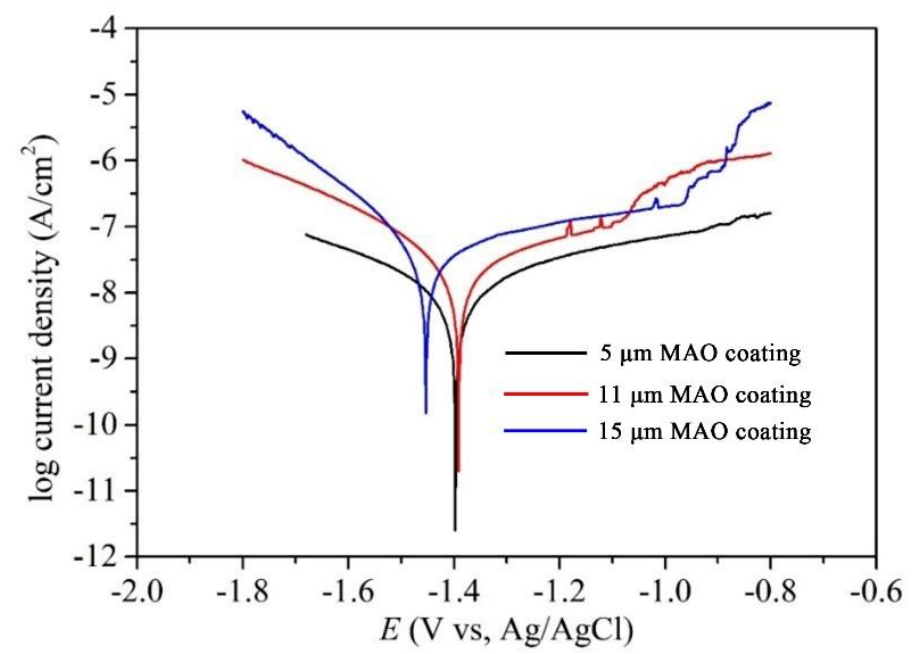

Figure 4. Potentiodynamic polarization curves of MAO coatings with different thickness in 3.5 wt.\% $\mathrm{NaCl}$.

Table 1. Electrochemical data from potentiodynamic polarization tests

\begin{tabular}{ccc}
\hline Samples & $E_{\text {corr }}(\mathrm{mV}$ vs. $\mathrm{Ag} / \mathrm{AgCl})$ & $i_{\text {corr }}\left(\mathrm{A} / \mathrm{cm}^{2}\right)$ \\
\hline $5 \mu$ m MAO coating & -1403 & $1.28 \times 10^{-8}$ \\
$11 \mu \mathrm{m}$ MAO coating & -1384 & $2.01 \times 10^{-8}$ \\
$15 \mu \mathrm{m}$ MAO coating & -1448 & $3.76 \times 10^{-8}$ \\
\hline
\end{tabular}

The results show that $E_{\text {corr }}$ moves towards the positive direction firstly with the increase of MAO thickness from $5 \mu \mathrm{m}$ to $11 \mu \mathrm{m}$, and then towards the opposite direction when the thickness reaches 15 $\mu \mathrm{m}$. The low corrosion current density of the three samples $\left(\sim 10^{-8} \mathrm{~A} / \mathrm{cm}^{2}\right)$ indicate that the corrosion resistance of the samples increased after MAO treatment. Compared with $5 \mu \mathrm{m}$ and $15 \mu \mathrm{m}$ MAO processed samples, coatings fabricated with $11 \mu \mathrm{m}$ illustrated superior corrosion protection properties. It indicates that the corrosion resistance of MAO coating is not growing monotonously with the increasing thickness. This may be attributed to the increasing size of MAO micropores (Figure 1a, $\mathrm{c}$ and e) with deposition time, which leads to decreases the corrosion resistance of MAO coating [25]. 
However, with the increase of time, the thickness of the dense layer of the micro-arc oxidation coating was the largest when the MAO coating was $11 \mu \mathrm{m}$, so the corrosion resistance of the coating did not increase with the increase of the thickness.

Electrochemical Impedance Spectroscopy (EIS) was further to evaluate the corrosion behavior of MAO coatings with different deposition time. The Nyquist plot in Figure 5a shows that MAO coating with $11 \mu \mathrm{m}$ has the maximum semicircles' radius. It indicates the highest impedance thus the highest corrosion resistance. In contrast, MAO coatings with $5 \mu \mathrm{m}$ and $15 \mu \mathrm{m}$ deposition exhibit lower values of impedance and corrosion resistance. It supports the conclusion in the last paragraph that the corrosion resistance of MAO coating is not growing monotonously with the increasing thickness. In the Bode plot (Figure 5b), the value of impedance modulus of $11 \mu \mathrm{m}$ deposition is highest among three samples, which verifies the result of Nyquist plot.
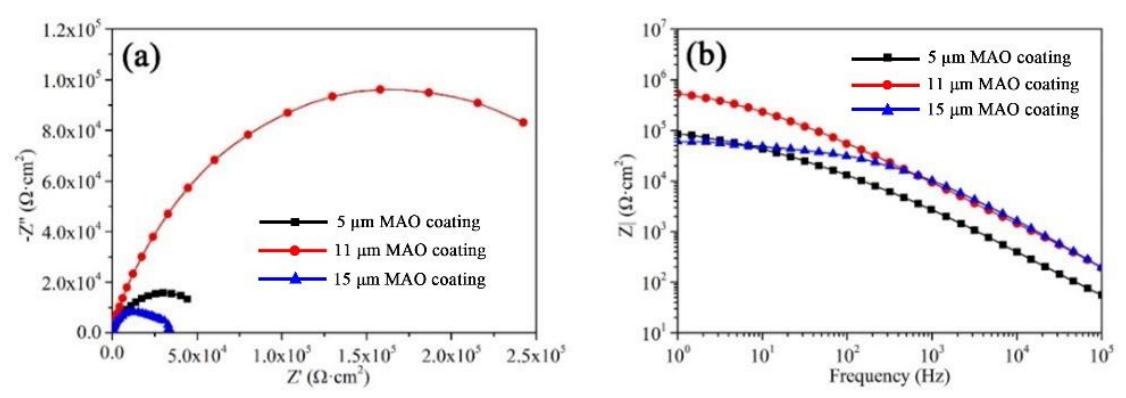

(d)
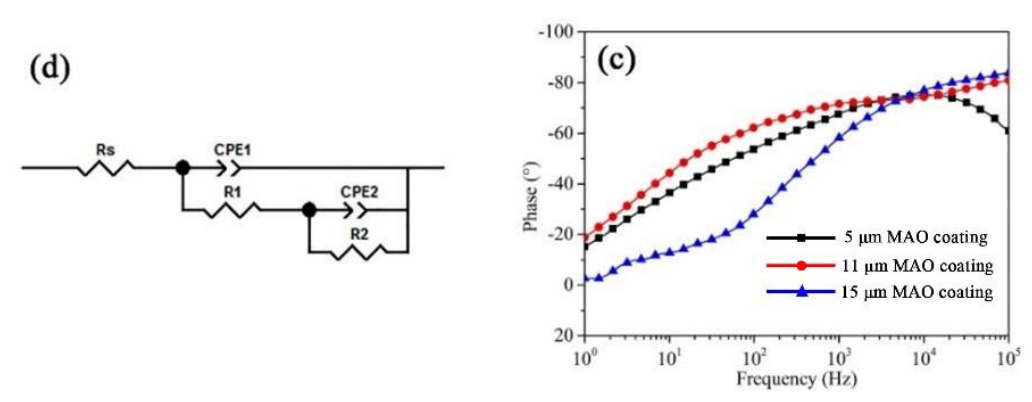

Figure 5. EIS with different thickness of MAO coating in 3.5 wt.\% NaCl: (a) Nyquist; (b) Bode; (c) Phase angle; (d) Equivalent circuit diagram.

Table 2. EIS fitting results for MAO coatings in $3.5 \mathrm{wt} . \% \mathrm{NaCl}$ solution.

\begin{tabular}{ccccc}
\hline Sample & $\mathrm{CPE}_{1}\left(\mathrm{~F} / \mathrm{cm}^{2}\right)$ & $\mathrm{R}_{1}\left(\Omega \cdot \mathrm{cm}^{2}\right)$ & $\mathrm{CPE}_{2}\left(\mathrm{~F} / \mathrm{cm}^{2}\right)$ & $\mathrm{R}_{2}\left(\Omega \cdot \mathrm{cm}^{2}\right)$ \\
\hline $5 \mu \mathrm{m}$ MAO coating & $2.16 \times 10^{-7}$ & $3.52 \times 10^{3}$ & $2.84 \times 10^{-6}$ & $5.96 \times 10^{4}$ \\
$11 \mu \mathrm{m}$ MAO coating & $6.85 \times 10^{-8}$ & $8.63 \times 10^{4}$ & $2.48 \times 10^{-7}$ & $6.35 \times 10^{5}$ \\
$15 \mu \mathrm{m}$ MAO coating & $3.76 \times 10^{-8}$ & $1.42 \times 10^{4}$ & $3.14 \times 10^{-6}$ & $2.82 \times 10^{4}$ \\
\hline
\end{tabular}

The schematic drawing of equivalent electrical circuit is given in Figure 5d [26]. It is plotted based on the EIS studies on MAO coatings to fit the experimental data. Rs is the resistance of solution; $\mathrm{R}_{1}$ is the resistance of porous outer layer of MAO coating and paralleled with a phase element $C_{P E} ; R_{2}$ 
represents the resistance of dense inner layer of MAO coating and paralleled with a phase element $\mathrm{CPE}_{2}$. The fitted results of the circuit elements are listed in Table 2, where the inner layer resistance $\mathrm{R}_{2}$ is higher than that of outer layer, $\mathrm{R}_{1}$.

Under the existing technological conditions, the resistance value of MAO coatings changes with the thickness and reaches a peak. Further increasing of thickness, the values resistance decrease. It's worth noting that the resistances $\mathrm{R}_{2}$ of the dense layer at all coating thickness are higher than those of the porous layer R1. The MAO thickness of the sample for $11 \mu \mathrm{m}$ has the highest corrosion resistance. The test results of corrosion resistance are consistent with the trend of the thickness of the MAO coating dense inner layer in Figure 1. It indicates that the dense inner layer plays a key role in MAO coating, protecting AZ31B alloy from corrosion In other words, the dense inner layer determines the corrosion protection properties of the whole MAO coating[27].

\subsubsection{Electrochemical test of MAO/EPD coatings}

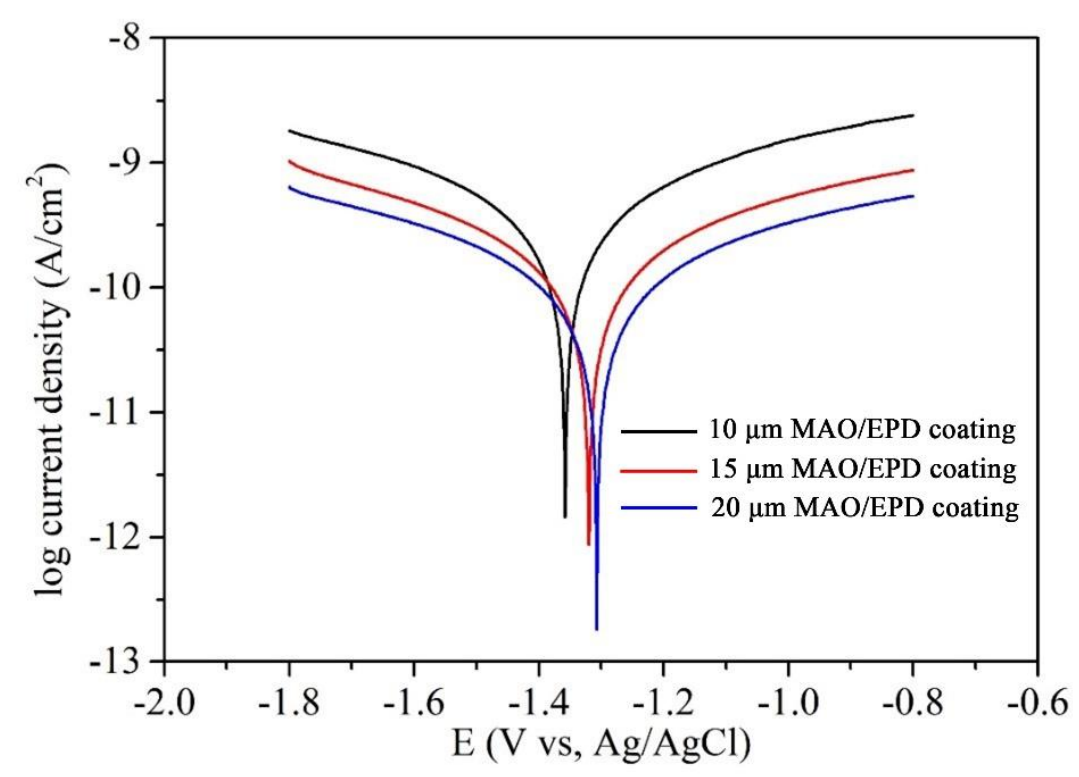

Figure 6. Potentiodynamic polarization curves of MAO/EPD coatings with different thickness in 3.5.wt\% NaCl.

Table 3. Electrochemical data from potentiodynamic polarization tests.

\begin{tabular}{ccc}
\hline Samples & $E_{\text {corr }}(\mathrm{mV}$ vs. $\mathrm{Ag} / \mathrm{AgCl})$ & $i_{\text {corr }}\left(\mathrm{A} / \mathrm{cm}^{2}\right)$ \\
\hline $10 \mu \mathrm{m}$ MAO/EPD coating & -1360 & $2.69 \times 10^{-10}$ \\
$15 \mu \mathrm{m}$ MAO/EPD coating & -1323 & $1.23 \times 10^{-10}$ \\
$20 \mu \mathrm{m}$ MAO/EPD coating & -1308 & $5.51 \times 10^{-11}$ \\
\hline
\end{tabular}

Figure 6 gives the potentiodynamic polarization curves of MAO/EPD coatings with different thickness. The results of electrochemical parameters $\left(E_{\text {corr }}\right.$ and $\left.i_{\text {corr }}\right)$ are listed in Table 3 , where $E_{\text {corr }}$ 
grows with the coating thickness from 10 to $15,20 \mu \mathrm{m}$, while $i_{\text {corr }}$ decreases from $2.69 \times 10^{-10}$ to $1.23 \times$ $10^{-10}, 5.51 \times 10^{-11} \mathrm{~A} / \mathrm{cm}^{2}$, It indicates that the corrosion resistance of MAO/EPD coating enhances with the increase of EPD coating thicknes. Compared with MAO coatings, all MAO/EPD coatings exhibited a higher corrosion potential and a lower corrosion current density (decreased 2 order of magnitude). It illustrated that the EPD composite treatment is capable of significantly increasing the corrosion resistance of MAO coating.
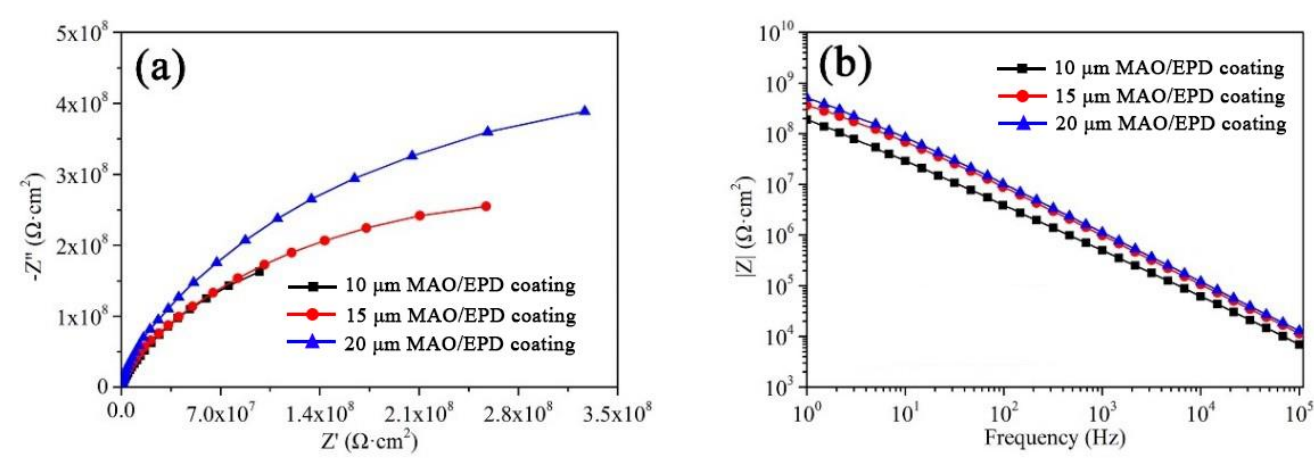

(d)
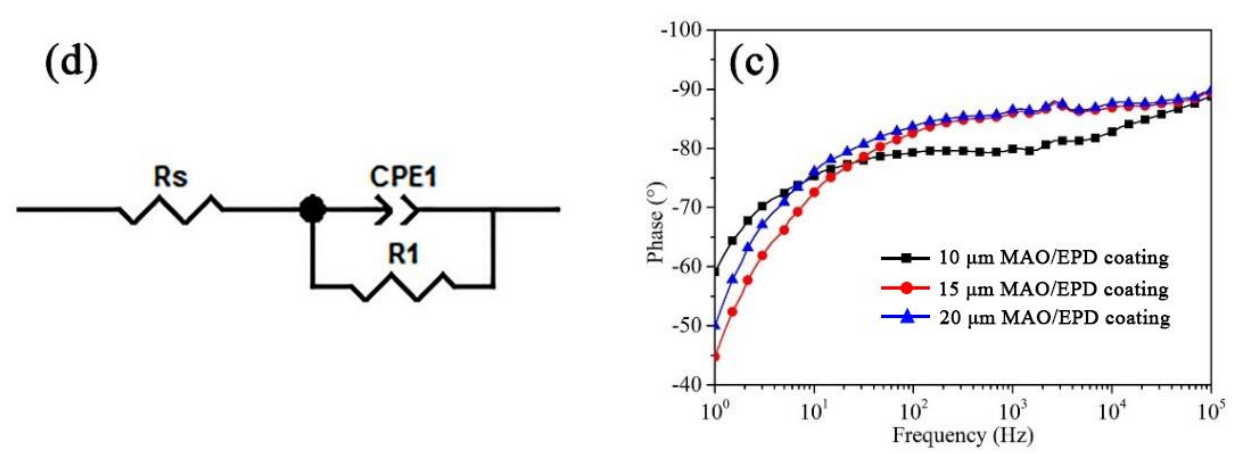

Figure 7. EIS of MAO/EPD coatings with different thickness in $3.5 \mathrm{wt} \% \mathrm{NaCl}$ : (a) Nyquist; (b) Bode; (c) Phase angle; (d) Equivalent circuit diagram.

To further study the electrochemical corrosion behavior of MAO/EPD coatings, the samples were tested by EIS, with the results shown in Figure 7. It can be seen from Nyquist plot and Bode plotin Figure $7 \mathrm{a}$ and $\mathrm{b}$ that the MAO/EPD coating with $20 \mu \mathrm{m}$ exhibits a maximum semicircles' radius and highest impedance modulus, indicating highest corrosion resistance. And the corrosion resistance of the MAO/EPD coating increases with the increasing deposition voltage.

Considering the Nyquist plot of MAO/EPD coatings shows only one capacitive loop in Figure $7 \mathrm{a}$ and the MAO/EPD coatings form an integral structure (Figure 2), the equivalent circuit model with series resistances is adopted and shown in Figure $7 d$. Rs is the resistance of solution; $R_{1}$ is the resistance of MAO/EPD composite coating and paralleled with a phase element $\mathrm{CPE}_{1}$. The fitted results are provided in Table 4.

As demonstrated by the EIS result, the resistance of the composite coating rises from $4.62 \times 10^{8}$, $4.81 \times 10^{8}$ to $7.72 \times 10^{8} \Omega \cdot \mathrm{cm}^{2}$ with the processing voltage increases, and the capacitance of the composite coating reduces from $8.33 \times 10^{-10}, 2.83 \times 10^{10}$ to $2.30 \times 10^{-10} \mathrm{~F} / \mathrm{cm}^{2}$. In other words, the corrosion resistance of the MAO/EPD composite coating increased with the increasing voltage of EPD 
treatment. At the same time, the resistance values of composite coatings are all in the order of $10^{8} \Omega \cdot \mathrm{cm}^{2}$, more than three orders of magnitude than those of MAO, It shows that MAO/EPD coatings all possess good corrosion resistance.

Table 4. EIS fitting results for MAO/EPD coatings in $3.5 \mathrm{wt} . \% \mathrm{NaCl}$ solution.

\begin{tabular}{ccc}
\hline Samples & $\mathrm{CPE}_{1}\left(\mathrm{~F} / \mathrm{cm}^{2}\right)$ & $\mathrm{R}_{1}\left(\Omega \cdot \mathrm{cm}^{2}\right)$ \\
\hline $10 \mu \mathrm{m}$ MAO/EPD coating & $8.33 \times 10^{-10}$ & $4.62 \times 10^{8}$ \\
$15 \mu \mathrm{m}$ MAO/EPD coating & $2.83 \times 10^{-10}$ & $4.81 \times 10^{8}$ \\
$20 \mu \mathrm{m}$ MAO/EPD coating & $2.30 \times 10^{-10}$ & $7.72 \times 10^{8}$ \\
\hline
\end{tabular}

\subsection{Immersion experiment}

The immersion experiment was used to study the degradation behaviors of MAO and MAO/EPD coated AZ31B. In order to compare the corrosion resistance of MAO samples with the best corrosion resistance and the MAO/EPD samples with the least corrosion resistance. Figure 8 shows optical microscopic images of the sample treated with MAO for $11 \mu \mathrm{m}$ and the sample treated with MAO/EPD thickness of $10 \mu \mathrm{m}$ during the course of the immersion experiment. Immersed in $3.5 \mathrm{wt} \% \mathrm{NaCl}$ solution for 53 hours, the MAO treated AZ31B began to show corrosion points (Figure 8a). After $149 \mathrm{~h}$, the entire surface was covered with corrosion pits. In contrast, in Figure 8b, there was no corrosion point in the whole process. The results indicate that MAO/EPD treatment significantly improved the long-term corrosion resistance of $\mathrm{AZ31B} \mathrm{Mg}$ alloy.

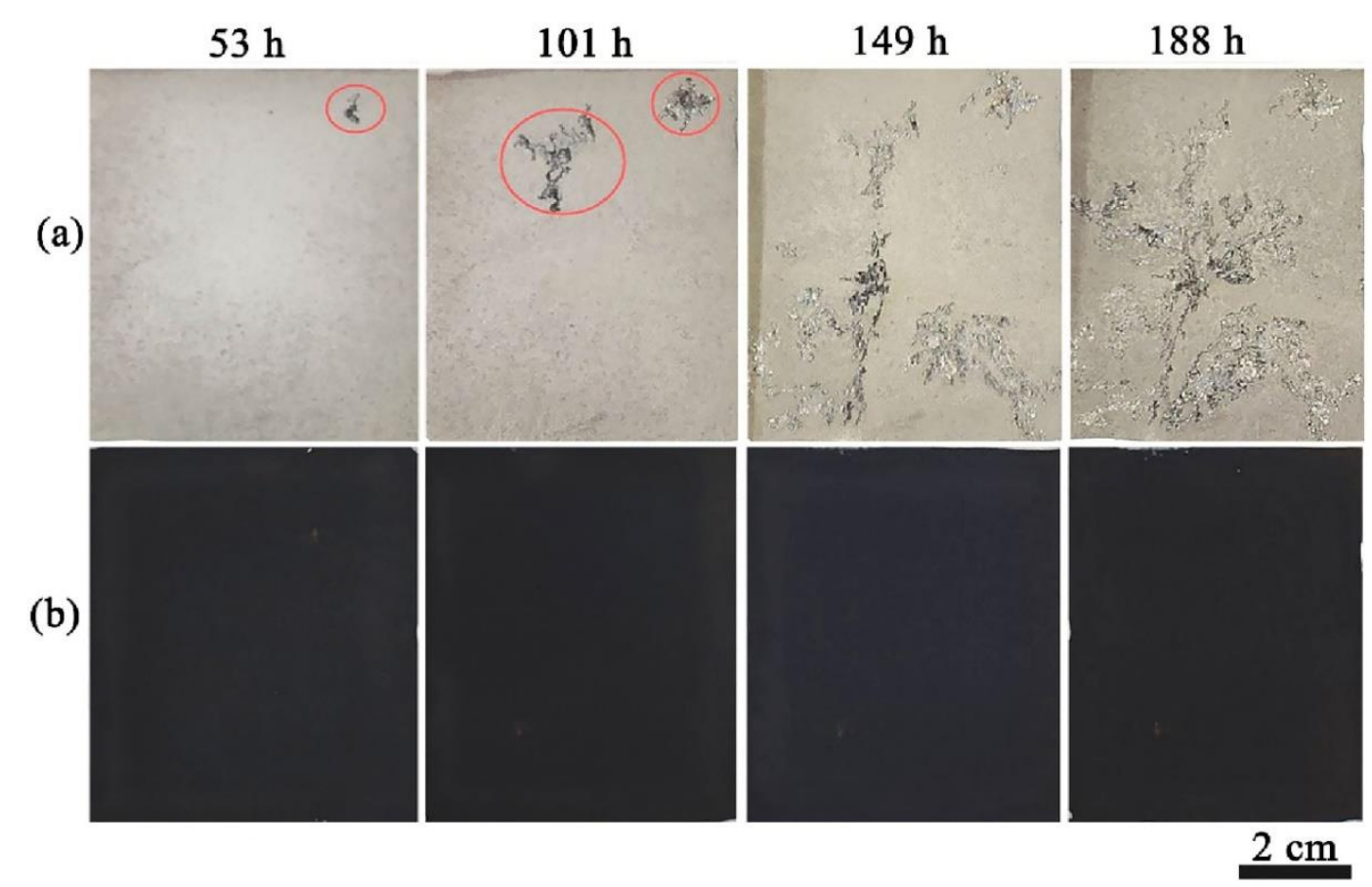

Figure 8. Optical microscopic images of the MAO (a) and MAO/EPD coated (b) AZ31B Mg alloy after immersion experiment for different times in $3.5 \mathrm{wt} . \% \mathrm{NaCl}$ solution. 
From the results of electrochemical tests and immersion experiment, both of MAO coating and MAO/EPD coating improve the corrosion resistance of the magnesium alloy, and MAO/EPD coating performs better. The schematic drawings of the protection mechanisms for both MAO and MAO/EPD coatings are illustrated in Figure 9. Due to the porous structure on the outer layer of MAO coating (Figure 9a), the corrosive substance is easy to pass through the porous layer, and intrude into and react with the dense layer, resulting in the damage of the MAO coating[28]. Then some corrosive medium penetrates through the MAO dense layer and reacts with the $\mathrm{Mg}$ matrix, resulting in corrosion of the magnesium alloy matrix (Figure. 8a). These corrosion spots should be developed from micropores and cracks on the surface of the MAO coating during the immersion process. As the thickness of the dense layer of the MAO coating increases, the difficulty of the corrosive medium penetrating the coating increases, and the corrosion protection ability of the coating on the magnesium alloy increases. Therefore, the dense layer of MAO coating is particularly important in the corrosion protection of magnesium alloys[25,26]. Therefore, the sealing of MAO coating is very important in improving the corrosion resistance.

After the composite treatment by electrophoresis, the pores of MAO coating are covered by the electrophoretic layer, forming a compact structure (Figure 9b). The entire EPD layer filled the micropores and micro-cracks on the MAO surface and prevented corrosive medium from penetrating into the coating, thus effectively improved the corrosion resistance of the alloy[29,30]. Moreover, EPD coating belongs to the organic category which has high chemical stability. It effectively prevented the corrosive substance from penetrating the EPD coating, as well as the formation of corrosion current[31]. With the increase of MAO/EPD coating thickness, the overall ability of to impede the corrosive medium was enhanced, so the corrosion resistance of the coatingwas increased. Both electrochemical tests and immersion tests confirmed that MAO/EPD coatings have excellent performance of corrosion protection.

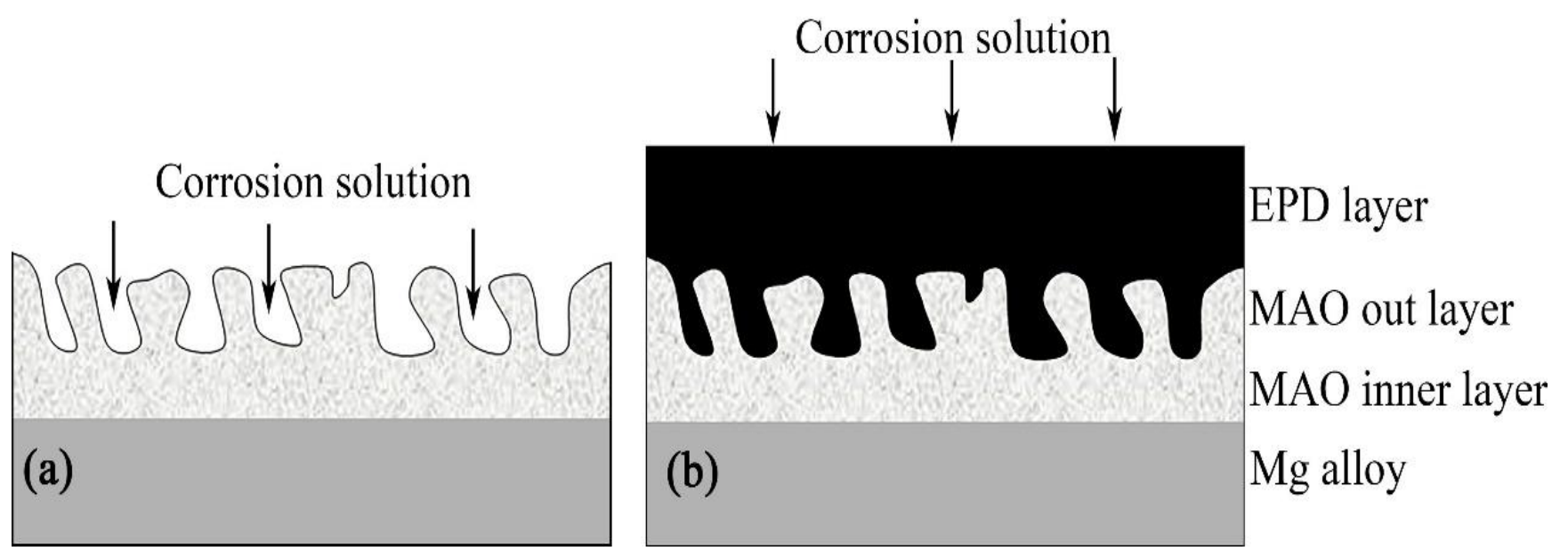

Figure 9. Corrosion protection schematic diagram of the MAO coating (a) and MAO/EPD coating (b).

\section{CONCLUSIONS}

MAO coatings and MAO/EPD coatings with different thickness were prepared on AZ31B Mg alloy. The corrosion resistance of MAO coatings is enhanced with the increase of coating thickness and 
closely related to the dense layer. The increase of EPD coating thickness resulted in insignificant enhancement of corrosion resistance for MAO/EPD composite coating. The resistance values are estimated in the order of $10^{8} \Omega \cdot \mathrm{cm}^{2}$.It means that MAO/EPD composite coatings has an improved corrosion resistance compared with MAP coating. It is mainly because the EPD coating composite effectively reduces the microporous and microcrack defects of MAO coating.

\section{ACKNOWLEDGEMENTS:}

This work was supported by the National Defense Basic Scientific Research Program of China [No. JCKY2018414C020] and National Natural Science Foundation of China [Grant Nos. 51571113, 51701094]. Y. Cui acknowledges the Prospective Joint Research Project of Jiangsu Province [SBY2016020451]. G. Xu and Y. Guo acknowledges the Natural Science Foundation of Jiangsu Province, China [Grant No. BK20171014] and the Priority Academic Program Development of Jiangsu Higher Education Institutions (PAPD).

\section{References}

1. M. K. Kulekci, Int. J. Adv. Manuf. Tech., 39 (2008) 851.

2. G. Song, A. Atrens, D. S. John, X. Wu, J. Nairn, Corros. Sci., 39 (1997) 1981.

3. R. Arrabal, E. Matykina, P. Skeldon, G. E. Thompson, J. Mater. Sci., 43 (2008) 1532.

4. D. Seifzadeh, Z Rajabalizadeh, Surf Coat Tech., 218 (2013) 119.

5. J. Sudagar, J. S. Lian, X. M. Chen, P. Lang, Y. Q. Liang, T. Nonferr. Metal. Soc., 21 (2011) 921.

6. R. G. Hu, S. Zhang, J. F. Bu, C. J. Lin, G. L. Song, Prog. Org. Coat., 73 (2012) 129.

7. Y. I. Choi, S. Salman, K. Kuroda, M. Okido, Corros. Sci., 63 (2012) 5.

8. A. Frignani, V. Grassi, F. Zanotto, F. Zucchi, Corros. Sci., 63 (2012) 29.

9. H.H. Elsentriecy, J. Qu, H. Luo, H.M. Meyer III, C. Ma, M. Chi, Thin Solid Films., 568 (2014) 44.

10. D. Veys-Renaux, E. Rocca, G Henrion, Electrochem. Commun., 31 (2013) 42.

11. D. Veys-Renaux, E. Rocca, J. Martin, G. Henrion, Electrochim. Acta, 124 (2014) 36.

12. R. O. Hussein, X. Nie, D. O. Northwood, Electrochim. Acta, 112 (2013) 111.

13. Q. Cai, L. Wang, B. Wei, Q. Liu, Surf Coat Tech., 200 (2006) 3727.

14. H. Tang, Y. Han, T. Wu, W. Tao, X. Jian, Y. Wu, F. Xu, Appl. Surf. Sci., 400 (2017) 391.

15. T. Hryniewicz, Metals, 8 (2018) 1058.

16. T. S. Narayanan, I. S. Park, M. H. Lee, Prog. Mater. Sci., 60 (2014) 1.

17. L. H. Li, T. S. Narayanan, Y. K. Kim, Y. M. Kong, I. S. Park, T. S. Bae, M. H. Lee, Thin Solid Films., 562 (2014) 561.

18. T. Yoshioka, A. Chávez-Valdez, J. A. Roether, D. W. Schubert, A. R. Boccaccini, J. Colloid Interf. Sci., 392 (2013) 167.

19. L. Besra, M. Liu, Prog. Mater. Sci., 52 (2007) 1.

20. X. Nie, A. Leyland, A. Matthews, Surf Coat Tech., 125 (2000) 407.

21. L. Zhao, C. Cui, Q. Wang, S. Bu, Corros. Sci., 52 (2010) 2228.

22. H. F. Guo, M. Z. An, H. B. Huo, S. Xu, L. J. Wu, Appl. Surf. Sci., 252 (2006) 7911.

23. A. Fattah-Alhosseini, M. S. Joni, J. Alloys. Compd., 646 (2015) 685.

24. A. Fattah-Alhosseini, M. S. Joni, Int. J. Mater. Res., 106 (2015) 282.

25. L. Shi, Y. Xu, K. Li, Z. Yao, S. Wu, Curr. Appl. Phys., 10 (2010) 719.

26. Y. Gu, C. F. Chen, S. Bandopadhyay, C. Ning, Y. Zhang, Y. Guo, Appl. Surf. Sci., 258 (2012) 6116.

27. M. S. Joni, A. Fattah-alhosseini, J. Alloys. Compd., 661 (2016) 237.

28. U. Malayoglu, K. C. Tekin, S. Shrestha, Surf. Coat. Tech., 205 (2010) 1793.

29. H. Duan, K. Du, C. Yan, F. Wang, Electrochim. Acta, 51 (2006) 2898. 
30. J. Wang, J. Tang, Y. He, J. Coat. Technol. Res., 7 (2012) 737.

31. C. Wang, B. Jiang, M. Liu, Y. Ge, J. Alloys. Compd., 621 (2015) 53.

(C) 2020 The Authors. Published by ESG (www.electrochemsci.org). This article is an open access article distributed under the terms and conditions of the Creative Commons Attribution license (http://creativecommons.org/licenses/by/4.0/). 